\title{
Design and Implementation of Hybrid Active Power Filter (Hapf) for UPS System
}

\author{
Mahendar Kumar ${ }^{1 *}$, Zubair .A Memon'1, M .Aslam Uqaili ${ }^{1}$ \\ ${ }^{1}$ Institute of Information \& Communication Technologies (IICT) \\ Mehran University of Engineering \& Technology (MUET), Jamshoro Sindh, 76090, PAKISTAN
}

DOI: https://doi.org/10.30880/ijie.2020.12.06.026

Received 20 February 2020; Accepted 19 July 2020; Available online 30 July2020

\begin{abstract}
Hybrid Active Power Filter (HAPF) is designed and applied for Uninterrupted Power Supply (UPS) System to mitigate harmonic currents in UPS during the power conversion from rectifiers to inverters (AC-DC-AC Converters). Various UPS types and topologies are used for continuous power supply without delay and protection to connected loads. In spite of the fact that UPS is one of the power quality apparatus but it has also drawback of disturbing the power system quality of system by current harmonics and voltage distortion during conversion of power. Passive and EMI Filters could not eliminate harmonics effectively from UPS system therefore it requires modern, rapid filtering method as well combination of Active and Passive Filters. Proposed model of HAPF for UPS System could mitigate current harmonics for optimal power transfer and minimize losses, increase overall efficiency, reliability and life span of equipment. Higher harmonic current and higher voltage distortion leads to greater power loss. In this paper the $(d-q)$ theorem is applied for the identification of harmonic currents. The $d-q$ theorem and calculation creates the signal of reference compensation current and this produced signal of current is tracked by the yield current of the voltage source converter.. Hysteresis based controller for HAPF is applied to create the switching signals to regulate and maintain the voltage source converter output currents. Harmonics and efficiencies are analyzed at different loads and on charging and discharging of batteries of various UPS System in different industries and sectors on the basis of experimental investigation then HAPF is designed and implemented. In simulation results, it is observed that THD reduced from 46 to $10 \%$, the harmonic currents were compensated and eliminated effectively which improved power quality of UPS System. Furthermore, addition of proposed HAPF could save the power up to $15 \%$ which lost due to poor power quality of UPS System.
\end{abstract}

Keywords: UPS, HAPF, d-q theorem, Reference Current, $\mathrm{V}_{\mathrm{dc}}$ Bus Regulator

\section{Introduction}

Nowadays every sector from industries, commercial to residential uses the Uninterruptable Power Supplies (UPS) System and power electronics devices due to their essential need of power and application however these are beneficial and vital for each sector but they produce harmonics in the power system. These harmonics generate electrical disturbance and distort waveforms which results in power loss due to poor power quality. That is why to enhance the standard of power provision this harmonic disturbance should be lowered with implementation of Passive, EMI and other Active Power Filters (APF) [1]. Energy security and reliability are present-day problems and unnecessary load shedding is a great issue in Pakistan as well as in other backward countries due to rising energy consumption demand and reduced provision. Reserve supply through UPS is a temporary remedy for customers in such circumstances. When national grid power is not available and primary source fails to recharge the batteries, UPS will supply power automatically and maintains a continuous Power without delay or transients [2]. During the power conversion in rectifier and inverters (AC-DC-AC Converters) harmonics currents and voltage distortion caused in Uninterrupted Power Supply UPS requires up to date and rapid filtering method to remove and mitigate harmonics in order to have desired power transfer, raise overall efficiency, reduce losses, enhance accuracy and lifecycle of apparatus. UPS offers instant protection which also makes power losses significantly due to harmonic current [3-6]. It is the need of the time 
to diminish harmonic disturbance to maintain an uninterrupted supply of important and sensitive loads and high quality electric power to the industries, power plants and other sectors like, data centers, hospitals and communication systems etc. Due to its unique load characteristics, extensive deployments of UPS will not only present challenges to power system but it will also create new possibilities. Hence for minimizing the range of harmonic currents in the electric power to industrial sectors. Hybrid Active Power Filters (HAPF) are ideally recommended according to the IEEE5191992 standards [5-7]. The current filtering approach suggests Hybrid Active Power Filter is hysteresis based for UPS System to mitigate harmonics currents, voltage distortion and optimal power transfer. The objective of this research is to address harmonic of UPS System and AC main supply form power system to explore the potential to increase reliability, minimize losses, optimal power transfer [9-15]. Passive and EMI Filters could not eliminate harmonics effectively from UPS system [16-22] therefore it requires modern, rapid filtering method as well combination of Active and Passive Filters [23-27] such as proposed model of HAPF for UPS System could mitigate current harmonics [28-34] for optimal power transfer, minimizing losses, increase overall efficiency, reliability and life span of equipment [1320]. To address harmonic filtering needs, a harmonic HAPF for UPS System has been proposed on basis of experimental results [7-8]. Classification is defined in Table-1 with different UPS Types \& Characteristics. The proposed model of HAPF for UPS Systems has been designed and implemented in simulation results showed Total Harmonic Distortion (THD) can compensate and eliminate the harmonic currents effectively as well as improve power system quality of UPS System. The operation and performance is verified with and without filters through simulations and furthermore addition of proposed HAPF is analyzed in saving the power which lost due to poor power quality of UPS System.

Table 1 - UPS Classification

\begin{tabular}{lcc}
\hline TYPE OF UPS & LIMITATIONS & ADVANTAGES \\
\hline Standby & Over 2KVA impractical & Cheaper, High Efficiency \\
Line Interactive & Over 5KVA impractical & High Reliability \\
Standby Online & Poor Efficiency, High Cost & Voltage Conditioning Excellent \\
Delta conversion Online & Impractical under 5KVA & High Efficiency \\
Double Conversion Online & Poor Efficiency and costly & Easy Parallel Operation \\
& & \\
\hline
\end{tabular}

\section{Experimental Harmonic Investigation \& Analysis of Single-Phase UPS Systems}

Single Phase UPS System of different types and various ranges from 2KVA to 10KVA are installed and used in different industries commercial, residential and other sectors for secure and reliable power [1-3]. Experimental and online results of Total Harmonic Distortion (THD), harmonic components and Efficiency on no-load, different loads, during charging and discharging of batteries of various UPS System has been investigated [7-8], calculated and analyzed. Single Phase UPS Systems has connected with different types of loads such as essential lighting Loads, Fans, DC Motors/ Machines results as shown in Figure-1, obtained with Single Phase Harmonic Analyzer, supply Voltage of UPS System is $220 \mathrm{~V}$ and load varied from $2 \mathrm{KVA}$ to $10 \mathrm{KVA}$, current harmonics varies and changes from THD of $15,30,33,70,75,76 \%$ with respect to connected load types. The THD analysis of UPS System is obtained and analyzed that how harmonics behave with no-load and connected to different loads like lighting Load, energy saver, tube light, Fans, DC Motors/ Machines and both together. Total Harmonic Distortion THD is a convenient approach to examine any nonlinear conduct of UPS systems which uses a Fast Fourier Transform (FFT). The calculated signal is obtained from the time spectrum to frequency spectrum [7] and investigated results are used for mathematical modeling of proposed HAPF for UPS System.

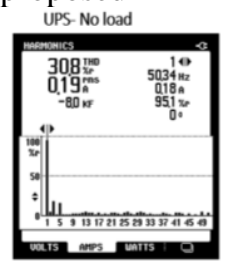

UPS connected to Both

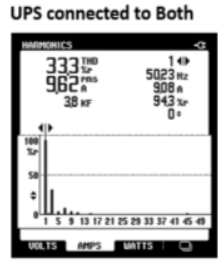

Fig. 1 - Experimnetal THD Analysis of Single-Phase UPS System
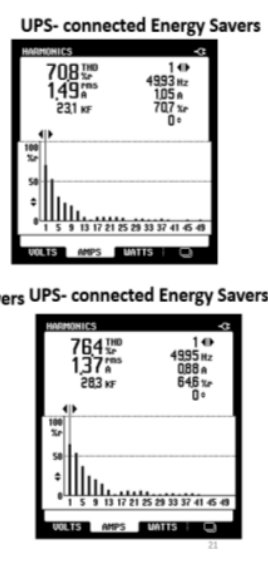

3. Experimental Harmonic Investigation \& Analysis of Three-Phase UPS Systems

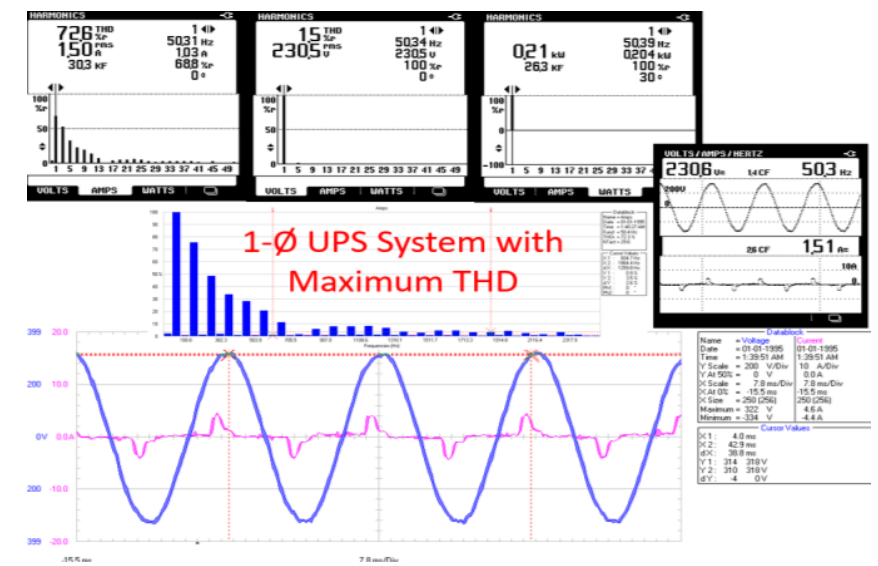


Three Phase 3-wire/4-wire UPS Systems of different types and various ranges from $10 \mathrm{KVA}, 30 \mathrm{KVA}$ to 110 KVA are installed and used in different industries, companies, hospitals, power generation, telecommunication and other sectors for secure and reliable power [1-3]. Experimental and online results of Total Harmonic Distortion (THD), harmonic components and Efficiency on no load, different loads, during charging and discharging of batteries of various UPS System has been investigated [7-8], calculated and analyzed. Three Phase UPS System has connected with different types of loads such as essential lighting, Emergency Loads, Fans, DC Motors/ Machines results as shown in Figure-2, obtained with Three Phase Harmonic Analyzer, supply Voltage of UPS System is 380/400 V and load varied from $10 \mathrm{KVA}, 30 \mathrm{KVA}$ to $110 \mathrm{KVA}$, current harmonics varies and changes from THD of 21,36,51\% with respect to connected load types. The THD analysis of UPS Systems is obtained and analyzed that how harmonics behave with noload and connected to different loads like lighting Load, light, Fans and Emergency Load DC Motors/ Machines and both together. Total Harmonic Distortion THD is a convenient approach to examine any nonlinear conduct of three phase UPS system which uses a Fast Fourier Transform (FFT). The calculated signal is obtained from the time spectrum to frequency spectrum [7-8] and investigated results are used for mathematical modeling of proposed HAPF for UPS System.

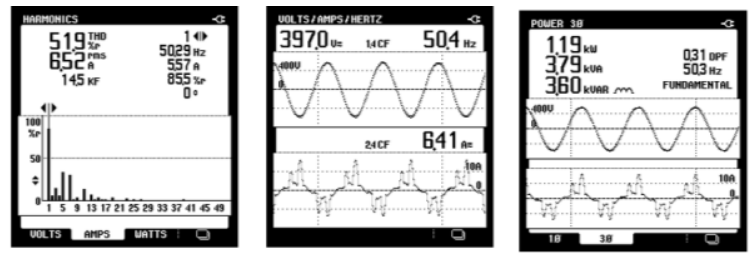

3- $\varnothing$ UPS System with Maximum THD 30 KVA UPS, 400 Volts

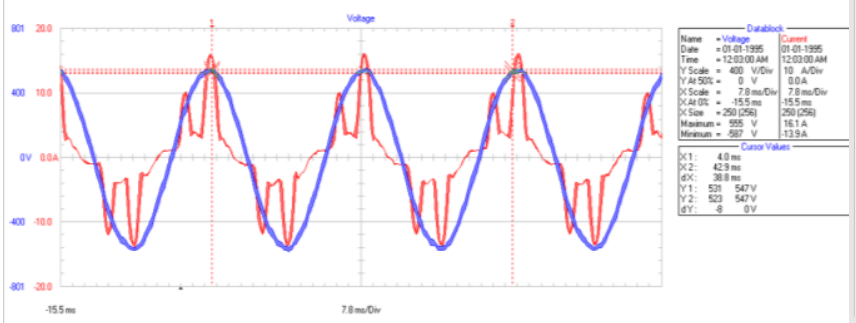

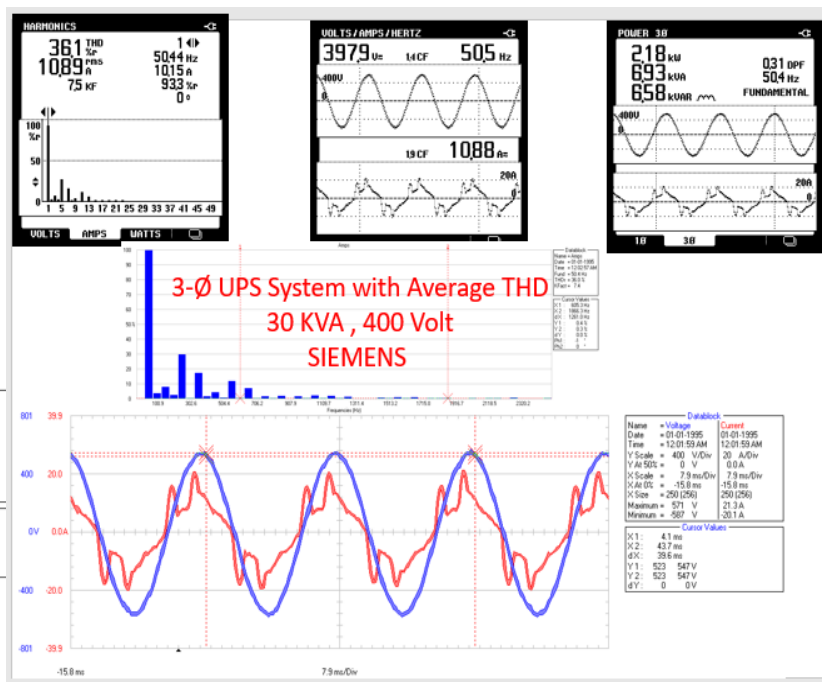

Fig. 2 - Experimnetal THD Analysis of Three-Phase UPS System

\section{Power Loss in UPS System owing to (AC-DC-AC) transformation and cause THD}

Pakistan power consumption is about 23,538 MW and loss of $1648 \mathrm{MW}$ which is $7 \%$ of total power consumption due to UPS System is shown in Table-2. In UPS Systems voltage and current harmonics are vital source of power loss. The power from $20 \%$ to $40 \%$ is lost because of converter and inverter losses in UPS Systems which has a very notable effect and also creates a gap of supply and demand [1-3]. Increasing gap causes excessive load shedding and power failure as well as electricity crisis. Table- 2 also shows the energy consumption of all provinces and losses due to THD in megawatt [2]. Hence, in such situation a UPS Systems are immediate and best solution for secure and reliable power but at the same time the also cause power loss ranging from $7 \%$ to $20 \%$ due UPS System harmonics. The consumer, end users of different industries and sectors if use the filtering techniques like EMI, Passive, Active Power Filters [916] and combination of both HAPF [17-24] that could save the power loss. It could be more effective and efficient to rectify THD with the proposed HAPF for UPS System that save the power loss $250 \mathrm{MW}$ which is about $15 \%$ of total loss.

Table 2- Pakistan Power Consumption and loss due to UPS System THD

\begin{tabular}{lcc}
\hline Provinces/ State & Power Loss in UPS $(\boldsymbol{M W})$ & Power Consumption $(\boldsymbol{M W})$ \\
\hline Punjab & 1036 & 14805 \\
Sindh & 332 & 4754 \\
KPK & 187 & 2683 \\
Baluchistan & 91 & 1294 \\
Total & 1648 & 23,538 \\
\hline
\end{tabular}

\section{Mitigation Techniques of Total Harmonic Distortion in UPS System}

There are different techniques and solutions to reduce harmonics in order to get desired output. Few of them are Capacitors, Compensators, EMI Filters, Passive filters, Dynamic Voltage Restorer (DVR), Active Power filters, and Unified Power Quality Conditioner (UPQC), Unified Frequency Quality Conditioner (UFQC) and Hybrid Active Power Filters (HAPF) [9-16]. The comparison of various harmonic alleviation techniques has been studied out by 
different researchers [17-34] and concluded that the HAPF is effective and more fast and modern filtering method. Therefore, the application of HAPF for UPS System is a novel work and shown effective result.

\subsection{Classifications of Active Power Filters}

The function is divided as the higher harmonics are filtered by passive power filter whereas the low-order harmonics filtered by Shunt active power filter, [8,12-14], Single line diagram and single line equivalent circuit and flow chart of Active and Hybrid Active Power Filters [15-20] classification are depicted in Figure-3(a), 3(b) and 3(c) respectively. In Series active power filter configuration one is linked in series and second behaves as a controlled voltage source. In Shunt active power filter configuration one is linked in parallel and second behaves as a controlled current source, where as Hybrid Active Power Filter (HAPF) configuration is a grouping and arrangement of active and passive filter. Technical constraint of ordinary APFs overcome with HAPF arrangement. It is combination of active and passive filters which has fast operation and rapid control with improved performance, compact size and cost-effective solutions as compare to other harmonic mitigation techniques like passive filters and multiples converter [20-27].

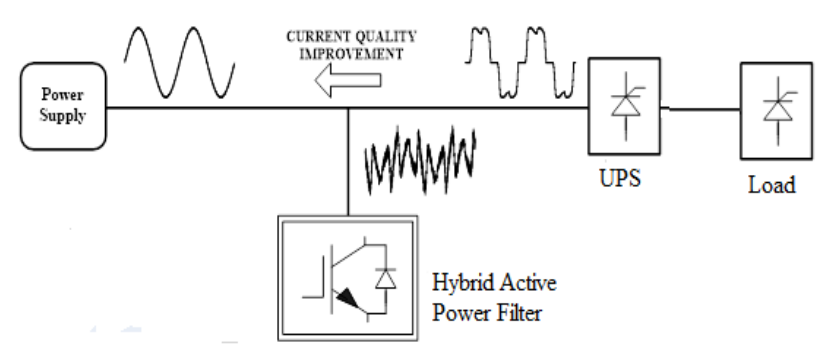

Fig. 3 - (a) Hybrid Active Power Single line diagram
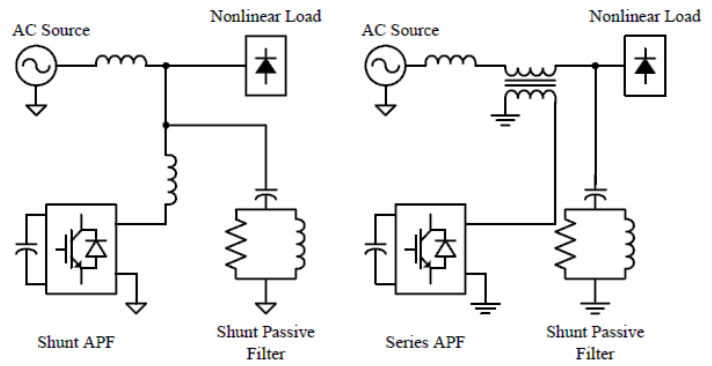

(b) Hybrid Active Power Single Line Equivalent Circuit

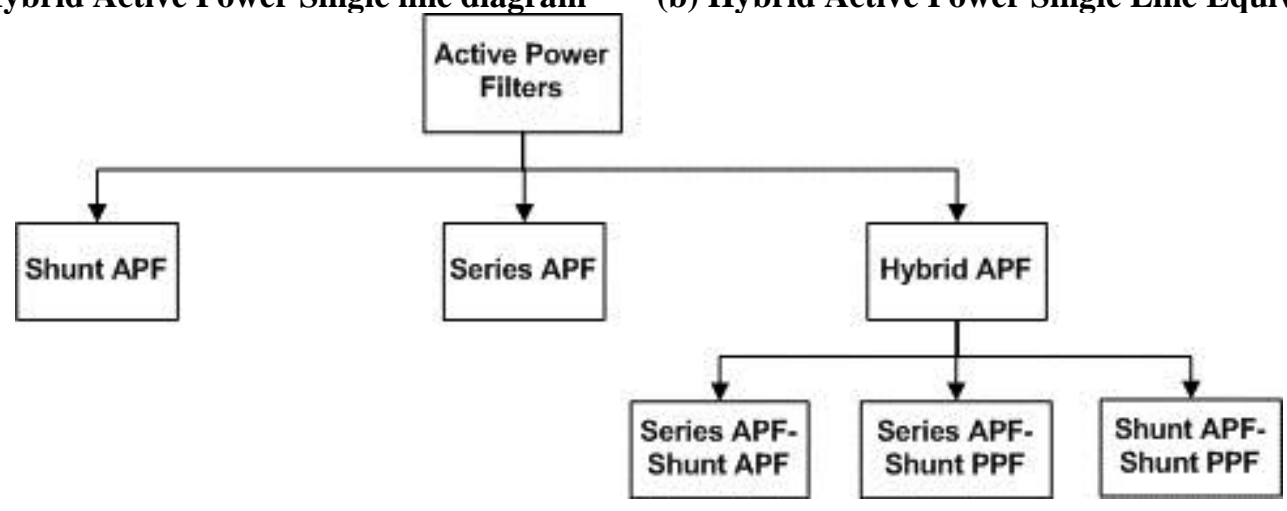

Fig. 3 - (c) Active and Hybrid Active Power Filters Classification

\subsection{Main Blocks in HAPF}

Power calculation block for obtaining voltage or current signal conditioning, reference synthesis and reference calculation, DC voltage regulator are the main components.

5.2.1. Signal conditioning: In this block reference synthesis has been estimated in terms of voltage and current level with high pass and low pass filter and detection or sensing of harmonics using the Time domain or Frequency domain. 5.2.2. Harmonic Extraction Controller: In this block calculation of compensating signal obtained from the disrupted wave comprise of both harmonic content and the fundamental wave. Mostly Time domain approach used like Instantaneous PQ Power Theory, DQ Theorem or Synchronous Reference Frame SRF Theorem, Synchronous detection method, Factious power consumption method, Synchronous Flux method, and Constant power factor method Constant Active power method [9,13]. Sometime Frequency domain approach used such as Fourier FFT Method, Sine Multiplication method, Modified Fourier Series method [16,21].

5.3.3. Creation of gating signal for harmonic compensation. There are lot of control methods like fuzzy control, SPWM, repetitive control, dead-beat control ,SVPWM, hysteresis, PWM, current control, sliding mode control, onecycle control and the artificial neural network (ANN) techniques can be applied to different configurations and arrangement of hybrid active power filters. [31-34].

\section{Mathematical Modeling and Simulation HAPF for UPS System Using DQ-SRF Method}

Mathematical modeling and simulation is made on the basis of online results of power quality analyzer and experimental results of Total Harmonic Distortion (THD), harmonic components and Efficiency on no load, different loads, during charging and discharging of batteries of various UPS System as result discussed above in section 2 and 3 
for single phase and Three Phase 3-wire/4-wire UPS System respectively. Mathematical modeling is developed for HAPF with Time domain approach based on d-q - SRF Theory [24-25]. For the harmonic compensation of UPS System average THD has been taken $46 \%$ for mitigation and after addition HAPF it is reduced to $10 \%$.

\subsection{Generation of Compensation Reference Current for HAPF Based On DQ- SRF Method}

Time spectrum based synchronous reference frame (SRF) theory works well in both dynamic state and steady state also proper control the power conditioner. Comparative analysis of various harmonic extraction methods is described [16-25] and for harmonic detection d-q synchronous reference frame has applied because of faster response. However, it needs an additional way of creating two fundamental sinusoidal signals $\sin (\omega t)$ and $\cos (\omega t)$ in quadrature and phase with UPS System supply for estimation. The harmonic current detection technique using d-q synchronous reference frame method is explained in Figure 4. The load current is converted to a synchronously rotating frame in such order that the fundamental content turn out to be DC quantity in d-axis that could be extracted with Low pass filter and in qaxis extracted reactive component for compensation.

\subsection{Mathematical Modeling of HAPF for UPS System Based On DQ- SRF Method}

The mathematical modeling of HAPF for UPS System on Synchronous Reference Frame theory (d-q method) is derived with Park's transformation related among the d-q reference co-ordinate current and three phase source current (a-b-c). The basic formation of dq-SRF technique consists of PLL-circuit for vector orientation and PI-controller has been applied for maintaining dc-link capacitor voltage [26]. Investigate source current and harmonic level from UPS System using d-q Synchronous Reference Frame method. The reference current signal for the operation and control of HAPF could be estimated and evaluated with the computation of load currents of all three phase (i $i_{\text {La }}, i_{L b}$, $\left.i_{L c}\right)$ in stationary coordinates are transformed into the two phase $\mathrm{d}$ - axis and q-axis rotating coordinates currents (id, $\mathrm{i}_{\mathrm{q}}$ ) as under in equations 1 to 4 .

$$
\begin{aligned}
& {\left[\begin{array}{l}
i_{a d} \\
i_{q}
\end{array}\right]=\frac{2}{3}\left[\begin{array}{lll}
\sin \theta & \sin \left(\theta-\frac{2 \pi}{3}\right) & \sin \left(\theta+\frac{2 \pi}{3}\right) \\
\cos \theta & \cos \left(\theta-\frac{2 \pi}{3}\right) & \cos \left(\theta+\frac{2 \pi}{3}\right)
\end{array}\right]\left[\begin{array}{l}
i_{L a} \\
i_{L b} \\
i_{L c}
\end{array}\right]} \\
& {\left[\begin{array}{l}
i_{I d} \\
i_{L q} \\
i_{10}
\end{array}\right]=\sqrt{\frac{2}{3}}\left[\begin{array}{ccc}
\cos \mu & \cos \left(\mu-\frac{2 \pi}{3}\right) & \cos \left(\mu+\frac{2 \pi}{3}\right) \\
-\sin \mu & -\sin \left(\mu-\frac{2 \pi}{3}\right) & -\sin \left(\mu+\frac{2 \pi}{3}\right) \\
\frac{1}{\sqrt{2}} & \frac{1}{\sqrt{2}} & \frac{1}{\sqrt{2}}
\end{array}\right]\left[\begin{array}{l}
i_{l a} \\
i_{l b} \\
i_{I c}
\end{array}\right]} \\
& i_{I d}=i_{I d}^{-}+\tilde{i}_{I d}^{\infty} \\
& i_{l q}=i_{I q}^{-}+i_{I q}^{\infty} \quad\left[\begin{array}{l}
i_{f d}^{*} \\
i_{f q}^{*}
\end{array}\right]=\left[\begin{array}{l}
i_{I d}^{\infty} \\
i_{I q}^{\infty}
\end{array}\right] \\
& {\left[\begin{array}{l}
i_{f a}^{*} \\
i_{f b}^{*} \\
i_{f a}^{*}
\end{array}\right]=\sqrt{\frac{2}{3}}\left[\begin{array}{cc}
\cos \mu & -\sin \mu \\
\cos \left(\mu-\frac{2 \pi}{3}\right) & -\sin \left(\mu-\frac{2 \pi}{3}\right) \\
\cos \left(\mu+\frac{2 \pi}{3}\right) & \sin \left(\mu+\frac{2 \pi}{3}\right)
\end{array}\right]\left[\begin{array}{l}
i_{f d d}^{*} \\
i_{f q}^{*}
\end{array}\right]}
\end{aligned}
$$

\subsection{DQ-Synchronous Reference Frame Block Diagram}

DQ-Synchronous Reference Frame block diagram and mathematical model is shown in Figure 4. Reference angle detection and the harmonic mitigation method; influence the dynamics and accuracy of HAPF. Sinusoid signal is prerequisite for obtaining requisite current in phase with the system for DC Link capacitor to control the voltage beside losses in the converter and mainly to draw the instantaneous basic component of load current. 

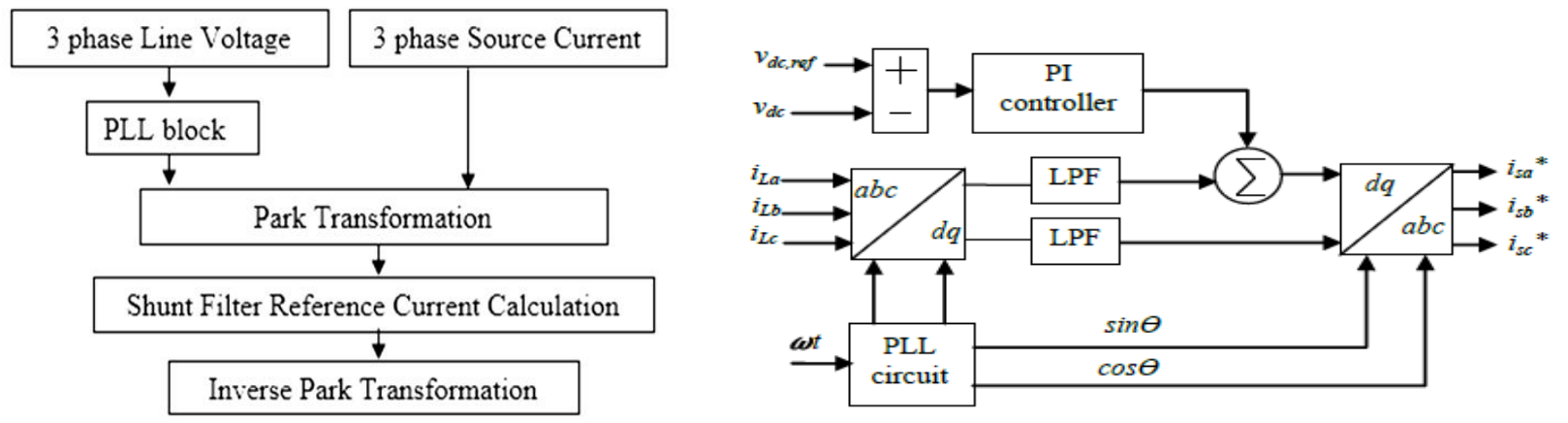

Fig. 4 - DQ- Synchronous Reference Frame Block Diagram and Mathematical Model

Synchronizing error will cause inaccurate estimation which leads to incorrect harmonic injection from HAPF. Therefore, exact Phase Locked Loop PLL [26] required extracting proper synchronizing signal. In single phase system, DQ transformation has been applied with fictitious or an imaginary signal is created with phase shifted of 90 degrees having same characteristics to real signal.

\subsection{Proposed DC Bus Voltage Regulator}

Reactive power transfer between bus DC Capacitor (Charges and discharges) and power could be drawn by the proposed HAPF. Power is to be provided to load and VSI to maintain the constant bus voltage DC Capacitor which lost due to capacitor leakage current or switching loss [27-30]. Bus DC Capacitor voltage dropped gradually until losses controlled [30]. Several control approaches that could be used for the DC bus voltage controller like PI, PID, Fuzzy, ANN controller or combination of any but in this research work simple PI controller utilized to regulate the DC bus voltage. PI Controller approach is based on proportional (top) and integral (center) as output added together $\mathrm{PI}(\mathrm{s})=\mathrm{Kp}+\mathrm{Ki} / \mathrm{s}$. Its design and implementation is shown in Figure 5; the voltage controller of DC bus works satisfactory. DC-bus Voltage controller manages DC side of the capacitor voltage on of the converter and remunerates losses of converter. Capacitor voltage is calculated and weighed to a fix value. In result, hybrid active power filters control and maintains the average DC voltage of capacitor in case of outside supply not available.

\section{PI Controller \& DC Voltage Regulator}

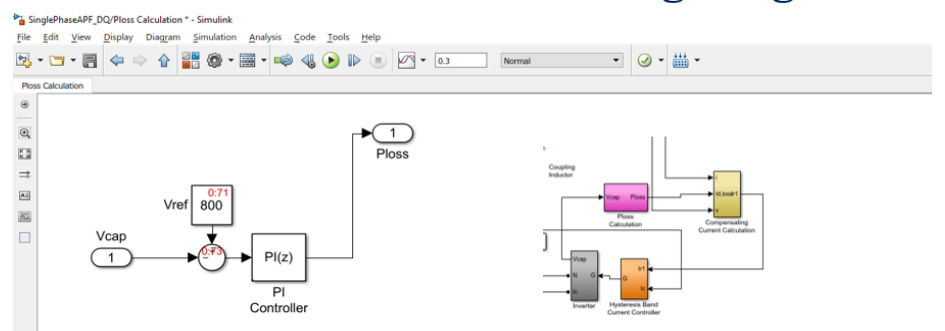

Fig. 5 - DC BUS Voltage Regulator with PI controller

\subsection{Proposed Hysteresis Controller - HAPF}

The Hysteresis controller is robust and applied to create switching and reference signals for VSI voltage source inverter to track the reference signal. It controls the output current created based on reference signal values [31-33]. A reference signal range is maintained and contrasted with the two inputs of the controller. Based on the error between the two inputs and the reference value, signals are generated. In VSI Turn "Off/on" interval of the switch is determined by error of the actual current and the reference current also dc voltage across the capacitor must be greater in order to maintain the compensation current continually. The bandwidth determines the permissible current estimated error.

I reference $=$ Reference Current and Ie $=$ Error Current

Limit of Lower HB hysteresis band $=$ I reference - minimum [ Ie ]

Limit of Upper HB hysteresis band $=$ I reference + maximum [Ie ]

Obtained, Hysteresis bandwidth $\mathrm{HB}=2$ XIe. 

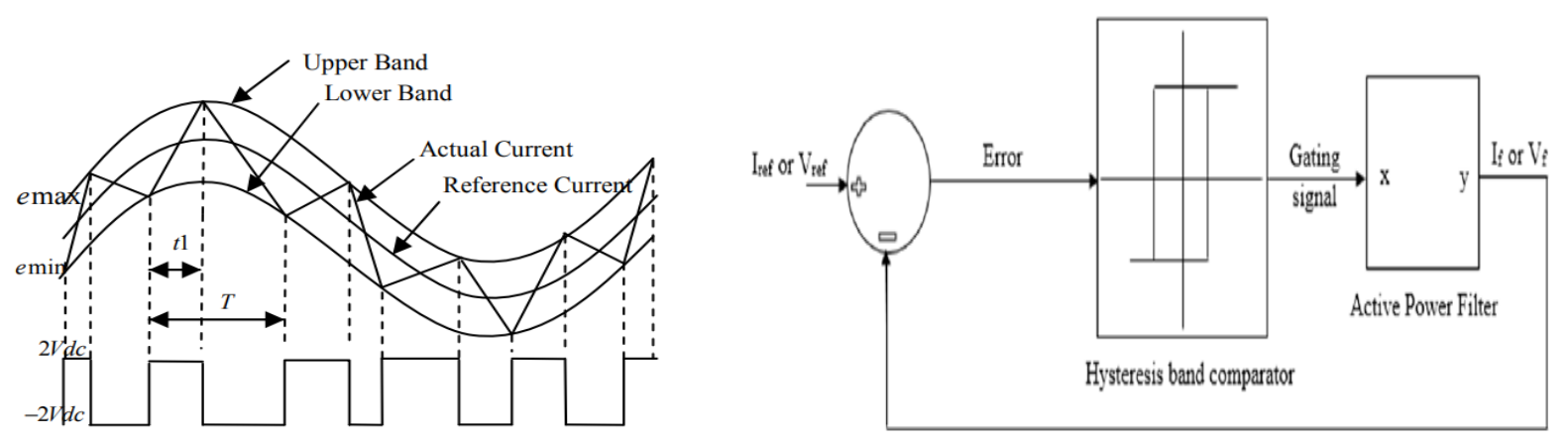

Fig. 6 - Hysteresis Controller working diagram and control block

\section{Simulation Model of HAPF for UPS System and THD / FFT Analysis}

The design and simulated model of Hybrid Active Power Filter for UPS System is shown in Figure 7. In this simulation, UPS System block having THD 46\% connected with proposed HAPF. Reference current for HAPF is obtained with d-q Synchronous Reference Frame method. Hysteresis controller is designed and developed to create switching pulse with PWM for voltage source inverter VSI to follow the reference signal and PI Controller is designed and implemented to manage and regulate DC Bus voltage and maintain the voltage of DC capacitor on inverter end.
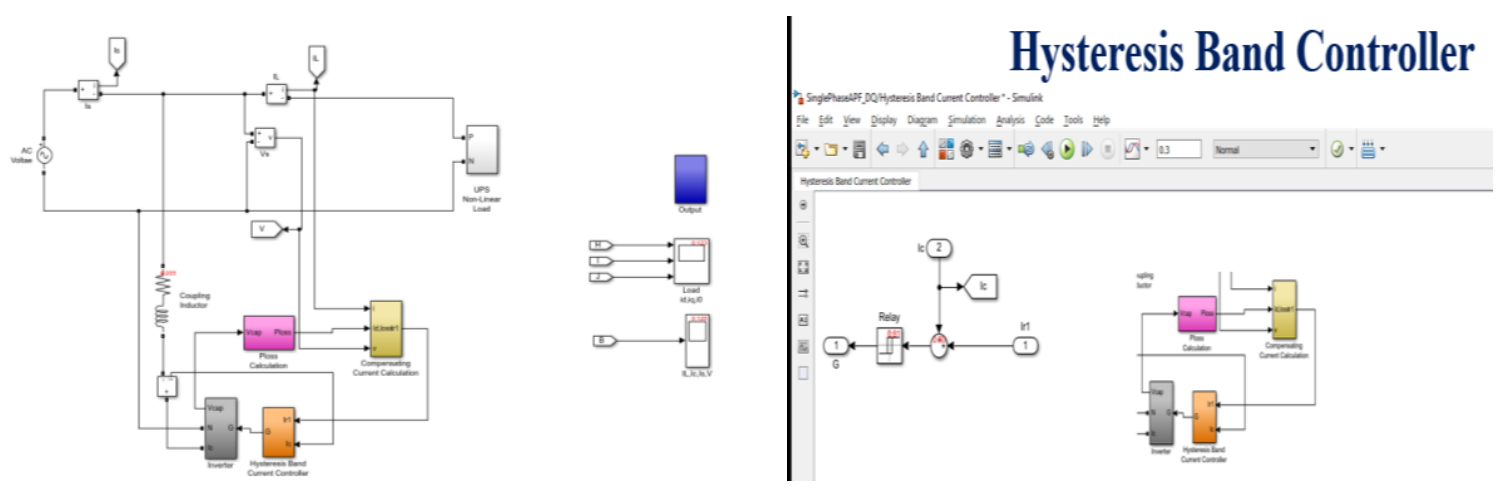

Fig. 7 - Simulation Model Hybrid Active Power Filter Hysteresis based for UPS System

\section{Total Harmonic Distortion - FFT Analysis with and without HAPF for UPS System}

The designed HAPF has been designed and implemented for UPS System on the basis of experimental results as shown in Figure 7. Total Harmonic Distortion THD analyzed with the FFT Tool in Matlab. The waveforms of THD source voltage, compensation current, load current and sources current are compared before and after applying filter. UPS System THD has obtained $46.58 \%$ without Filter as shown in Figure 8 (a) and UPS System THD has been reduced to $10.45 \%$ with desgined HAPF as depicted in Figure 8 (b). UPS System block having THD $46.58 \%$ before filter and THD $10.45 \%$ after implementation of proposed and designed HAPF.

Measured THD $=\mathbf{4 6 . 5 8} \%$ Before Filter

FFT-Analysis of Load Current IL

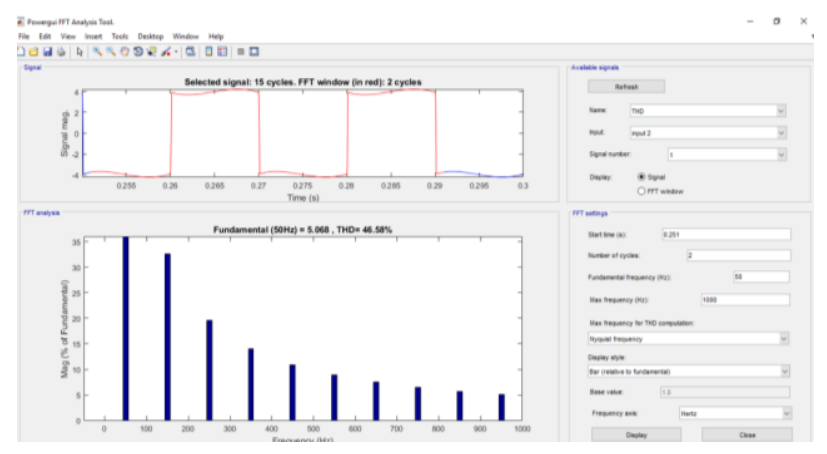

Fig. 8 - (a) UPS System THD= $\mathbf{4 6 . 5 8 \%}$ without Filter
Measured THD $=\mathbf{1 0 . 4 5} \%$ After Filter FFT- Analysis of Source Current Is

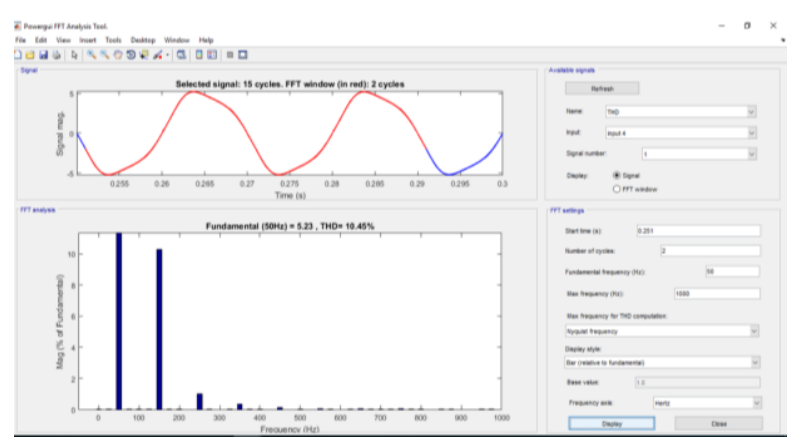

(b) UPS System THD= $\mathbf{1 0 . 4 5 \%}$ with HAPF 


\section{Results \& Discussion: Design \& Implementation of HAPF for UPS System}

Uninterruptable Power Supplies (UPS) System is commonly applied and installed in electric power system to meet energy security, reliability as well protection at the same time UPS also creates harmonics and disturb the power system quality. Specially, local manufactured UPS are installed that have huge losses and high harmonics contents also low battery charging and discharging efficiency as mentioned under in Table 3.

Table 3 - UPS System Efficiency \& THD

\begin{tabular}{ccccc}
\hline $\begin{array}{c}\text { Charging } \\
\text { Efficiency }\end{array}$ & $\begin{array}{c}\text { Discharging } \\
\text { Efficiency }\end{array}$ & $\begin{array}{c}\text { Overall } \\
\text { Efficiency }\end{array}$ & $\begin{array}{c}\text { UPS Without } \\
\text { Filter THD }\end{array}$ & $\begin{array}{c}\text { UPS with Proposed Filter } \\
\text { HAPF THD }\end{array}$ \\
\hline $80 \%$ & 50 to $74 \%$ & 45 to $60 \%$ & 40 to $70 \%$ & $10 \%$ \\
\hline
\end{tabular}

It is observed that UPS System THD without filter is $46.58 \%$ and with proposed HAPF, THD is reduced to $10.45 \%$ which shows a significant difference. low power quality influence and big concern of electric power system as a result high THD causes power loss, unnecessary circuit breakers tripping and power transformers overheating, increase rate of equipment damage, useful equipment lifetime reduced with certain proportion.

Table 4 - Power saved with proposed Hybrid Active Power Filter for UPS System

\begin{tabular}{lccc}
\hline UPS with / without filter & Consumption (MW) & $\begin{array}{c}\text { UPS Power } \\
\text { Loss (MW) }\end{array}$ & \% Loss \\
\hline UPS without THD Filter MW Loss & 23538 & 1648 & $14.28 \%$ \\
UPS with THD Filter MW Loss & 1648 & 1391 & $0.04 \%$ \\
Proposed HAPF Saving in MW & & 257 & $14.243 \%$ \\
[Saving =15\%] & & \\
\hline
\end{tabular}

The proposed HAPF for UPS System compensated and eliminated the harmonic currents effectively as well improved power quality of UPS System and furthermore addition of proposed HAPF could save the power about $14.23 \%$ as shown in Table 4. It is investigated that minimizing the harmonic contents and Total Harmonic Distortion (THD) in a remarkable proportion with proposed Hybrid Active Power Filter for UPS System confirms optimal power transfer and saved more than $15 \%$ energy during conversion.

\section{Conclusion}

In this article, HAPF for UPS System is designed and implemented to eliminate harmonics effectively, improve power quality of UPS System and save the power. HAPF is designed based on DQ-SRF method for reference current therefore it operates well in both dynamic and steady states and controls the operation with hysteresis controller for switching of VSI. Also PI Controller has been designed for maintaining and controlling DC Bus Capacitor Voltage. THD analysis, performance and efficiency have been carried out experimentally of various Single Phase and Three Phase UPS System at different loads during charging and discharging of batteries. On the basis of experimental results, HAPF for UPS is designed and implemented and THD analysis performed before and after applying filter which are shown through simulations. As UPS System with application of HAPF utilization in hybrid energy storage sources and also interconnection and integration with micro and smart electric grid leads a new area of innovation and study. Electric Power System reliability, availability, dynamic stability and steadiness obtained from various energy resources integration with UPS System but improved performance and power quality of UPS system with suggested HAPF was dire need of the time and learning opportunity in many aspects. In simulation HAPF with hysteresis-based controller has improved THD from $46.58 \%$ to $10.45 \%$. As power loss in transformation from AC-DC-AC in UPS System or in chargers could be saved up to $15 \%$ or more. Several ways are there to mitigate distortions like using compensators, passive filters and multi-pulse converter which are less efficient, complex, costly and large in size whereas HAPF are better than the rest of the technologies, robust in operation, controlled and compact in size and cheaper. This proposed technique could be orientation and direction for the different sections of society like researchers, inventors, end users, and manufacturers. As research is unending in any field therefore keeping in view the importance and application of UPS, the research will indefinitely intact to offer more efficient and intelligent control to the industries.

\section{Acknowledgements}

Author acknowledges gratitude to higher authorities and Institute of Information and Communication Technologies MUET Jamshoro for extending their cooperation, help, funding and facilities in accomplishing research. 


\section{References}

[1] Kumar, M., Memon, Z. A., Uqaili, M. A., \& Baloch, M. H. (2018). An Overview of Uninterruptible Power Supply System with Total Harmonic Analysis \& Mitigation: An Experimental Investigation for Renewable Energy Applications. INTERNATIONAL JOURNAL OF COMPUTER SCIENCE AND NETWORK SECURITY, 18(6), 25-36

[2] Arshad, Naveed, and Usman Ali. "An analysis of the effects of residential uninterpretable power supply systems on Pakistan's power sector." Energy for Sustainable Development36 (2017): 16-21

[3] Kwon, B. H., Choi, J. H., \& Kim, T. W. (2001). Improved single-phase line-interactive UPS. Industrial Electronics, IEEE Transactions on, 48(4), 804-811

[4] Khadem, S. K., Basu, M., \& Conlon, M. F. (2011). Parallel operation of inverters and active power filters in distributed generation system-A review. Renewable and Sustainable Energy Reviews, 15(9), 5155-5168

[5] Zhan, Y., Guo, Y., Zhu, J., \& Li, L. (2015). Performance comparison of input current ripple reduction methods in UPS applications with hybrid PEM fuel cell/supercapacitor power sources. International Journal of Electrical Power \& Energy Systems, 64, 96-103

[6] Zhao, B., Song, Q., Liu, W., \& Xiao, Y. (2013). Next-generation multi-functional modular intelligent UPS system for smart grid. IEEE Transactions on Industrial Electronics, 60(9), 3602-3618

[7] Memon, S. H., Kumar, M., Memon, A. H., Memon, Z. A., \& Soomro, S. A. (2018). Total Harmonic Distortion (THD) Analysis of Grid Integrated Permanent Magnet Synchronous Generator (PMSG) With Full Scale Converter (FSC) Based Wind Farm. IJCSNS, 18(12), 232

[8] Memon, Z. A., Uqaili, M. A., \& Soomro, M. A. (2011). Experimental Analysis of Harmonic Mitigation Effects on Three Phase Six Pulse Converter by Using Shunt Passive Filter. Mehran University Research Journal of Engineering and Technology, 30(4), 653-656

[9] Mebrahtu, F. (2020). Harmonic Mitigation Techniques in Smart Distribution Network. In Handbook of Research on New Solutions and Technologies in Electrical Distribution Networks (pp. 104-118). IGI Global

[10] Naderi, Y., Hosseini, S. H., Ghassemzadeh, S., Mohammadi-Ivatloo, B., Savaghebi, M., Vasquez, J. C., \& Guerrero, J. M. (2020). Power quality issues of smart microgrids: applied techniques and decision making analysis. In Decision Making Applications in Modern Power Systems (pp. 89-119). Academic Press

[11] Salam, Z., Tan, P. C., \& Jusoh, A. (2006). Harmonics mitigation using active power filter: A technological review. Elektrika, 8(2), 17-26

[12] Memon, Z. A., Uqaili, M. A., \& Unar, M. A. (2012). Estimation of compensation current reference using fuzzy logic controller for three-phase hybrid active power filter. International Journal of Computer Applications, 43(11), $16-21$

[13] Memon, Z. A., Uqaili, M. A., \& Unar, M. A. (2016). Design of Three-Phase Hybrid Active Power Filter for Compensating the Harmonic Currents of Three-Phase System. arXiv preprint arXiv:1604.03223

[14] Biswas, P. P., Suganthan, P. N., \& Amaratunga, G. A. (2017). Minimizing harmonic distortion in power system with optimal design of hybrid active power filter using differential evolution. Applied Soft Computing, 61, 486496

[15] Busarello, Tiago \& Silva, Newton \& Vendrusculo, Edson \& Pomilio, Jos $\cong$ @. (2012). A control approach based on frequency response for line harmonic current mitigation using hybrid active power filter. 237-243. 10.1109/EnergyCon.2012.6347759

[16] Omran, M. A., Mohd, I. I., Almelian, M. M., Dawood, M. A., \& Al-izzi, M. Y. (2018). Shunt hybrid active power filter based on two compensation strategies with PI and fuzzy logic controllers. Journal of Telecommunication, Electronic and Computer Engineering (JTEC), 10(1-3), 75-79

[17] Gong, C., Sou, W. K., \& Lam, C. S. (2020). Second-Order Sliding Mode Current Controller for LC-Coupling Hybrid Active Power Filter. IEEE Transactions on Industrial Electronics

[18] Omran, M. A., Mohd, I. I., Ahmad, A. Z., Almelian, M. M., Samsuri, F., Sujod, M. Z., ... \& Salem, M. (2020). Utilization of Filter Harmonic Current Based on Shunt HPF Within the Acceptable IEEE-519 Standard. In InECCE2019 (pp. 849-858). Springer, Singapore

[19] Kim, J. W. (2020). Back to Back Active Power Filter for Multi-Generator Power Architecture with Reduced dclink Capacitor (Doctoral dissertation, Virginia Tech)

[20] Wu, J., Liu, T., Qiu, T., \& Xu, D. (2020). Current and power quality multi-objective control of virtual synchronous generators under unbalanced grid conditions. Journal of Power Electronics, 1-10

[21] S. RAHMANI, A. HAMADI, N. MENDALEK, AND K. AL-HADDAD, "A New Control Technique for ThreePhase Shunt Hybrid Power Filter," Industrial Electronics, IEEE Transactions on, vol. 56, pp. 2904-2915, 2009

[22] Ferrari, M. (2018, June). Evaluation of Harmonic Detection Algorithms for Active Power Filter based on Voltage and Current Detection Methods. In 2018 9th IEEE International Symposium on Power Electronics for Distributed Generation Systems (PEDG) (pp. 1-8). IEEE 
[23] Asiminoaei, L., Blaabjerg, F., \& Hansen, S. (2005, March). Evaluation of harmonic detection methods for active power filter applications. In Applied Power Electronics Conference and Exposition, 2005. APEC 2005. Twentieth Annual IEEE (Vol. 1, pp. 635-641). IEEE

[24] Gonzalez, M., Cardenas, V., \& Pazos, F. (2004, October). DQ transformation development for single-phase systems to compensate harmonic distortion and reactive power. In Power Electronics Congress, 2004. CIEP 2004. 9th IEEE International (pp. 177-182). IEEE

[25] Saitou M., Matsui N. and Shimizu T.(2003): "A control Strategy of Single Phase Shunt Active Power Filters Using a Novel dq Transformation”, Industry Applications conference 2003. 38th IAS Annual Meeting Record.

[26] Chung, S. K. (2000, May). Phase-locked loop for grid-connected three-phase power conversion systems. In Electric Power Applications, IEE Proceedings-(Vol. 147, No. 3, pp. 213-219). IET

[27] Abdelkader, A. B., Abdelkhalek, O., Bousserhane, I. K., Hartani, M. A., \& Omari, A. (2019). A comparative study and experimental validation on single phase series active power filter control strategies using PI, FLC and sliding mode controllers. Int J Pow Elec \& Dri Syst, 10(2), 731-743

[28] Talebkhah, A., Shadlu, M. S., \& Fatemi, S. M. (2019, February). Control Strategy of a Single Phase Active Power Filter with Adjustable DC Link Capacitor Voltage for THD Reduction in Non-linear Loads. In 2019 10th International Power Electronics, Drive Systems and Technologies Conference (PEDSTC) (pp. 606-611). IEEE

[29] Bayindir K. c.; E Muammer "Understanding the modelling and analysis of a shunt active power filter using MATLAB/Simulink" International Journal Of Electrical Engineering Education, Vol. 43, No 3, pp. 185- 205,2006

[30] Huynh, T., Minh, L., Van Ho, C., Tien Nguyen, X., \& Vu Tran, T. (2019). Improving the Adaptive Effecting for Active Power Filter Using Fuzzy Control in the DC Link Voltage's Stability Controller. International Journal of Mechanical Engineering and Technology, 10(3)

[31] Kale, M., Ozdemir, E. "A novel adaptive hysteresis band current controller for shunt active power filter," Electric Power System Research, voL73, February 2005

[32] Puhan, P. S., \& Sandeep, S. D. (2020). Real Time Neuro-Hysteresis Controller Implementation in Shunt Active Power Filter. In Advances in Decision Sciences, Image Processing, Security and Computer Vision (pp. 355-363). Springer, Cham

[33] Dwivedi, A., \& Tiwari, A. N. (2017). Analysis of three-phase PWM rectifiers using hysteresis current control techniques: a survey. International Journal of Power Electronics, 8(4), 349-377 